\title{
Push and Pull Theories of Desire
}

The basic idea of this paper is as follows: there are two different approaches to desire, first, an externalist, naturalistic, and causalistic and, second, an internalist, normative and cognitivist approach. The first approach considers the motivational push essential when the second concentrates on the pull of desirability. In other words, an agent is driven by a drive or he is attracted by the intentional object of desire. I will indicate how to combine these two approaches. Also, I will show how all this helps us understand the variable strengths of desire. This is a difficult and somehow intractable problem. I utilize first F.H. Bradley's interesting analysis of desire in his unduly neglected Ethical Studies (2. edition, 1927) and then move on to Bertrand Russell's account of a pseudonaturalistic type of a push theory in his classical The Analysis of Mind (1921). Russell develops interesting and challenging ideas for example concerning unconscious desire and human happiness.

\section{Background Checks}

Kant in his Metaphysics of Morals writes rather enigmatically, "Lust is called unnatural if one is aroused to it not by a real object but by his imagining it, so that he himself creates one, contrary to natural purpose; for in this way imagination brings forth a desire contrary to nature's end." Unnatural love is a "violation of duty to oneself." 1 As I read this, unnatural desire is a matter of pull and natural of push. An example of the latter is hunger that makes you oriented towards nourishment (natural object), and of the former a gourmand's imagination that creates desirable illusions of fine dishes (unnatural object). You should do what is right, which pushes you in the natural direction and turns you away from fantasies - these are as empty and unpredictable as they are haphazard. Natural desires do not depend on imagination, or if imagination is involved, it emerges automatically, that is, without implying the agent's personal contribution. We do not say the agent actively imagines; we say some images appear to him. This is a push theory of desire. The problem is that many instances of push are dangerous and unethical. The agent may be aroused by

1 I. Kant, Metaphysics of Morals. Tr. M. Gregor. Cambridge: Cambridge University Press, 1797/1966, 6:425. Cf. Kant's definition of desire, 6:211. 
not so laudable objects such as violence and murder. Be this as it may, we say natural desires depend on a special class of push generated mental states and processes.

Perhaps the easiest way to distinguish between the push and pull theories of desire is to use Thomas Nagel's distinction between motivated and unmotivated desires. Push theories deal with unmotivated desires. Nagel says the former "assail us" but the latter are "arrived at by decision and after deliberation." The first description is given in terms of a metaphor (assail), which seems to be apt but at the same time incongruent with the second, perfectly literary or metonymic idea (deliberation and decision). My suggestion is to say that the push theories work without reasons and pull theories utilize reasons that allow one to identify an object as desirable. Think about the desire to eat. My relevant bodily deprivation pushes or drives me towards food and eating: if I believe it is food I make an attempt to eat it. But suppose the food is repulsive, or not desirable, which may well stop the drive. Obviously, the push and pull are not fully independent of each other, except if hunger is very strong. This does not refute the idea that push desire fails to employ reasons - the point is, the source of desire is elsewhere and reasons are just side-constraints.

The next question is, what should we say about Nagel's idea of decision and deliberation? The idea of deliberation may sound odd in this context: normally, the emergence of desire does not depend on deliberation although the selection of its object may show an influence of deliberation. I want a new car and then I choose the brand and the individual vehicle after deliberating it. Finally, I tell the sales person I want this particular vehicle. This may be true but we may still ask, can I decide on the basis of deliberation that I want a new car? Suppose I want a new car because my old is a wreck, it stopped working, and I need a car. Thus, I have my perfectly good reasons for wanting a new car. When I deliberate my situation, I notice that I want a new car, but to say that I decide to desire a new car is certainly beside the point. The relevant desire hits me when I notice that I have my reasons that make a new car a desirable proposition. De dicto, I want a new car on the basis of my considerations or deliberations of the desirability of a new car in my current life situation. But, de re, I do not have an object of desire yet. It is impossible to go and buy a car simpliciter. If you go to a dealership and say "I want one new car, please," they will think you are out of your mind. Now you must make a decision concerning exactly what kind of car you want. I wonder if this de re case is what Nagel has

2 T. Nagel, The Possibility of Altruism. Oxford: Oxford University Press, 1979. See the discussion by G.E. Schueler, Desire. Cambridge, MA: MIT Press, 1995, pp. 16-17. 
in mind? You need to reach a stage in the life of the desire when you are able to say, "I want this vehicle" and point to it. Next, you may or may not form an intention to buy it. Its price tag may stop you from buying it.

I am not sure, however, at what stage the decision comes into the picture, at the level of de re desire or the intention to buy a particular vehicle. I suspect the correct idea is to say that intention and deliberation belong together, which is to say that the de re desire may not be based on a decision. You work your way through all the alternatives until you find what you want and then it is time to decide whether to buy it or not, which means an intention to buy or no intention at all. ${ }^{3}$ What has happened is that you start with your de dicto desire and the relevant desirability conditions, you specify them step by step until you have a definite description of a relevant object, and there you have a de re object of desire. Notice that you work all the time at the level of desirability conditions and only in a secondary sense at the level of desires. Desires as if emerge because of the given desirability conditions, given the relevant, complex beliefs concerning the situation. In this perspective, we might invoke the idea of supervenience: desire supervenes on the desirability conditions of its intentional object plus the beliefs concerning the relevant background facts. Of course, Nagel is correct if he says you can deliberate on the desirability conditions, not always but at least sometimes. Some of them just appear to you or are undeniable, like beauty, pleasure, and intuitive moral goodness. A beautiful object is intrinsically desirable; whether you desire it or not depends on your beliefs concerning the case. You cannot decide whether beauty is desirable or not and neither can you decide on what you believe. Of course, you may deliberate on whether the object is truly beautiful and whether your beliefs are valid, but that is all. In sum: I follow the Nagel's lead by saying that push theories need not mention reasons unlike pull theories. Pull desires are motivated because they are dependent of their desirability conditions.

Now, the key problem concerning any naturalistic push theory of desire concerns actions; the pull theories of desire have no essential connection to action or bodily behaviour. I can desire in situations where action is not possible. For instance, my desire entails an intention not to act or to stay passive. Push theories, on the contrary, look as if they were necessarily action oriented, or are they? Desire, as such, is not a motive for action, and thus if push theory is going to be a theory of desire, it must allow for push without action. This is to say some push desires or drives have only mental consequences just like some pull desires that only shape one's mental landscape. Of course, push desire can

3 On desire and intention, see my "An Introduction to Desire," Homo Oeconomicus 31 (2014), 447-461, pp. 449-450. 
do the same. Here we need to imagine a case in which one does not refrain from action merely because of one's beliefs, for instance, that the action is too costly. We need an example of a case where action is impossible because of its description; the description is then intrinsically non-actionist. An example of the first case is, "I was hungry but I did not start eating because the top dog wanted food." I am not sure good examples of the second case exist; all the possible cases look actionist in nature, like "I am afraid of him and therefore I want to be quiet." Notice that you need not deliberate your fear that brings about quiescence. This is an actionist case in disguise. Perhaps this works: "I want Bill dead," uttered by a person who is deeply committed to non-violence but who passionately hates Bill. Now his hatred brings about the push towards the death of Bill as the object of his desire. Yet, I do not want to kill Bill. In what follows, I suppose drives are desires along with the motivated pull desires. I will specify the relation between the two types of desire at the end of this paper. ${ }^{4}$

A good example of actionist push theory of desire comes from F.H. Bradley, who writes in his Ethical Studies,

The essence of desire for an object would thus be the feeling of our affirmation in the idea of something not ourself, felt against our feeling of ourself as, without the object, void and negated; and it is the tension of this relation which produces motion. ${ }^{5}$

I call this definition negative, actionist, and semi-naturalistic. The definition also makes explicit a traditional, actually Platonic, but today often neglected problem, namely, whether the proper object of desire is positive or negative. Most philosophers today seem to think that desire is dependent on something positive whereas the tradition says it is all negative. A person is not complete without the object of desire, and therefore, when she believes this is the case she also desires the object, or she is driven to desire the object. Bradley's definition above is Platonic in that he speaks of the inner void and personal negation in the sense that what I lack is, metaphorically, like an open gash in my soul. If I desire something that logically entails that I miss it or I do not have it. Moreover, this lack is anxious, or the person feels she is "void and negated." We cannot desire what we already have, this is true, and hence I always desire what I do not have. But this is not all that Bradley and the Platonists say.

4 Aristotle systematically distinguishes between push and pull theories, or irrational and rational desires; see G. Pearson, Aristotle on Desire. Cambridge: Cambridge University Press, 2012, p. 201.

5 F.H. Bradley, Ethical Studies. Oxford: Oxford University Press, 1927, p. 68. 
They drastically simplify the idea of what a person does not have by making the lack categorical in the sense that without it the person is not what she should be. This is an oversimplification as the lack may as well be relative and conditional.

Suppose I want money. Does this fact logically entail that I (categorically) do not have money and, hence, this is the reason why I want it? If this is so, my categorical lack of money is a negative state of affairs that psychologically speaking indicates an anxious mental state, which I need to attend to and also amend. When the world changes favourably and I get money the mental disturbance vanishes, which is to say the relevant desire is satisfied. An obvious problem then arises, namely, my lack of money is a problem only if I find money desirable and I desire money. This makes the lack conditional on a desire. If I do not desire money, however good and desirable I may find moneyed existence, I am fine even when I do not have money, which is to say that the idea of the negatively characterized object of desire is problematic to the core. In other words, the categorical negative characterization of the lack of money itself cannot be a part of the definition of the relevant desire. We need a conditional characterization, that is, lack of money is bad only on the condition that you want money. The idea of lack logically entails a relevant desire when we mean a painful or otherwise disturbing deficiency. Looking back to Bradley's definition, I certainly do not want to be "void and negated"; on the contrary, I want to be fully and positively recognized or recognizable.

What happens when I have money and I still want more money? In this case the lack of money is relative and conditional. If I already have money I cannot want money simpliciter, because you cannot want what you have, but I can want more money. In a way, I lack money but only in a relative sense. Also, if I want more money than I already have the previous logical problem concerning the characterization of lack does not matter. Now I have money and I want more of it: I want more only if I want money; if I want money, I want more money. This is unproblematic. To want more looks like a positive characterization although it also implies a relative lack. Therefore, I can still say I lack money, that is, the money that I now want. A rich man thinks he sorely lacks something, that is, more money. If he had enough he would not want more, as he may argue, but because he still lacks so much, compared to what is enough, he wants more. This example shows that the problem of the negative or positive characterization of the desired change of the world is a bogus problem. The difference between them is semantic or stipulative. More money or love is always a good thing as such but on the other hand it entails a definite and permanent but relative lack of the good thing. This looks like paradox: as long as you desire you must feel that you are missing something, although you just want more of it. Your desire for one more million or an extra 
lover is not an expression of real lack of something good; what you want is more of the good thing. A major difference obtains between a person who has no money or love and the person who has plenty but never enough. What we see here is something like greed in action. Therefore, both Bradley and, as we will see, Russell are wrong, however different their philosophical perspectives may ultimately be.

Another way of putting the same point concerning the positive and negative characterizations of desire is in terms of enjoyment and felt relief. Sometimes you desire an object that brings you pure enjoyment, like a new car, or you may serve and satisfy your greed by getting more money. Sometimes you aim at equilibrium, as in the case where lack of love troubles you and therefore you want to find love. The result is relief. In this way the aim of your positive desire is enjoyment and negative desire relief, which in itself is an emotionally neutral mental episode.

How does Bradley's theory deal with the problem of desirability and its relation to actual desiring? The problem is that one can desire anything, including perhaps harming oneself. ${ }^{6}$ Some philosophers have explained desirability in terms of pleasure, value, or reward. Accordingly, one finds an object worth desiring because one hopes to find pleasure, the object appears to be valuable, or it is believed to be rewarding as such. To hurt one's enemy may not be valuable or even pleasurable but it certainly is rewarding. Binge drinking of alcohol may bring about pleasure even if it is not rewarding as such and hardly valuable either. To donate money for the poor is not pleasant but it may be rewarding, and it certainly is valuable. Such considerations prove nothing, though, since for instance Bradley refers to the tension within that drives the agent to move and act on her desire in order to relieve the tension, as he calls it. All kinds of potential sources of tension exist but some of them become actual and even urgent so that they bring about action. It is hardly necessary to adopt Bradley's simple actionism without qualifications. According to his theory, the goal of desiring is to remove a felt tension that is a type of mental pain. Therefore, the object of desire is pain reduction - I already argued against such an idea.

What brings about desire, according to Bradley, is not the desirable object as such; what brings about desire is the lack of the object or the fact that I do not possess it. I focus on the object more or less clearly, at least so clearly that I can

6 See H. Pickard, "Self-Harm as Violence: When Victim and Perpetrator Are One." In Women and Violence: The Agency of Victims and Perpetrators, H. Widdows and H. Marway (Eds.). London: Palgrave Macmillan, 2015, pp. 71-90; and M. Stocker, "Desiring the Bad: An Essay on Moral Psychology," Journal of Philosophy 76 (1979), 738-753. 
see what I miss - this is painful and then my desire emerges. Notice that this explanation does not apply to small and personally insignificant types of lack. Yet, when told in this way the push theoretical narrative is naturalistic or in this sense causalistic: I aim at something I believe to be desirable and I feel the void when I face the lack or the loss of the object. This I experience as mental tension that feels like pain and finally I formulate a desire that may lead to action, the context allowing. Also notice Bradley's account of desirability: I find desirable anything that alleviates my bad feeling of being "void and negated." If I want to be a good father I indeed will feel void and negated as long as I am not a good father. Once the world changes so that I am a good father all is well; or, all is well as long as I believe I am a good father.

Anyway, the main point is that desirability alone cannot generate desire. It is only when the lack of the desirable object becomes painful enough in a suitable context that desire emerges in order to compensate for the loss and the lack in one's soul. However, as I said above, such a negative theory is not so easy to accept. In some cases no such tension may occur. As I said above, the problems concentrate around small desires. Suppose I want ice-cream. I find it difficult to believe that anyone would feel "void and negated" without a cone of ice-cream. Here the lack of ice-cream (push) may not be important at all compared to the temptation of eating ice-cream (pull). Suppose I want beer but I also feel it may be a bad idea. Hence, the lack of beer does not feel bad at all but having a beer still feels wonderfully tempting. Indeed, both the lack of the desired object and having it may be tempting, as long as having it remains more so.

\section{Russell on Desire}

In his Analysis of Mind, Bertrand Russell first presents an account of the cognitive theories of desire and then his own naturalistic and behaviourist ideas. He divides the theories into push and pull theories. ${ }^{7}$ I suppose he knew Bradley's views because he certainly knew his main theories and works. In his own times, Bradley was famous and his books widely read: sic transit gloria mundi. Push theories are similar to Bradley's theory, which says an agent is pushed to formulate a desire and then act on it because of the painful tension he feels. Or, as he says, the tension brings about motion. A pull theory is a theory according to which the agent feels the pull or attraction of the desirable objects he faces,

7 See also A. Kenny, Action, Emotion and Will. London: Routledge \& Kegan Paul, 1969, Ch. v. 
or perhaps he imagines them. Desirability entails attraction and focuses on a hope for, say, a reward or relief. The two theories can be summarized as follows:

Push Theory: An agent feels unpleasantly disturbed and then she either withdraws from the situation or compensates for the feeling of displeasure by doing something appropriate; if she believes that she can do something about the disturbance she desires whatever it is.

Pull Theory: The person finds an object desirable and as such attractive in the sense that it promises so much situational good that the agent believes he now has a good reason to consider it, which entails the relevant desire.

Also an irrational version of pull theory may exist, namely, I have a reason not to desire although I still do. I desire $\mathrm{X}$ although I know $\mathrm{X}$ is definitely not going to happen, which constitutes a reason not to desire, or rationally I should not desire X. In such cases, I may use a special counterfactual expression like "I would have liked X to happen." For example, more indirectly "I should have been a male model," when it did not happen - which masks the desire in question, or "I would have wanted X to happen." ${ }^{\text {"T }}$ This expresses a kind of nostalgia for my long-lost opportunity to desire for X. I will argue that both theories are needed when one develops a full theory of desire. The pull theory is inadequate alone because it cannot explain the urgency or strength of some desires; the push theory is too stubbornly actionist and, moreover, it cannot handle hope - in this sense it is not a complete theory. Surprisingly, at least some push theories can accommodate wish-fulfilment.

Let us now concentrate on Bertrand Russell's version of the push theory, which he defends energetically, although not always with clarity or care, in his hastily composed little book. Say, I am itching, which is a highly motivating feeling, in the sense that I want to stop it. No more itching is my desired psychological equilibrium state, and thus I am driven to act accordingly: I scratch. ${ }^{9}$ If I cannot, I am still inclined to act, or I would scratch if I could; and I know in normal conditions I can do so. Moreover, my beliefs concerning the desire related states of affairs are supposed to be valid. In other words, I believe I can alleviate the relevant bad feelings by certain means when the feeling brings about my desire, whose Russellian, radically revisionist push definition is as follows:

8 In some languages, e.g. in Finnish, Spanish, Italian, and French this is a normal way of describing the situation; in French, j'aurai voulu (Futur antérieur).

9 See S. Freud, Beyond the Pleasure Principle. Tr. J. Strachey. New York: Norton, 1920/1961, pp. 3-4. 
The initial mental occurrence involving discomfort is called a "desire" for the state of affairs that brings acquiescence.

Desire has a purpose:

The state of affairs in which this condition of quiescence is achieved is called the "purpose" of the cycle. ${ }^{10}$

The discomfort in question brings about action towards the state of affairs whose occurrence alleviates it. For this to happen, the person must entertain a belief to the effect that the desired remedy works as intended. This is a push theory because "[we] must suppose that the stimulus to the performance of each act is an impulsion from behind, not an attraction from the future." Or, in other words, what we have here is "a push, not a pull, an impulsion away from the actual, rather than an attraction toward an ideal."11 This sounds clear.

Russell's theory is simple if it merely says that some states of discomfort are connected to beliefs concerning their alleviation and hence desire refers not to anticipated disappearance of the discomfort but to the fact of discomfort itself. In other words, I desire anything that I believe will bring about quiescence or status quo or equilibrium of the mind. The question is, what is the object of desire? Example: I want money and that indicates an uncomfortable state of disequilibrium, or a desire. I can fix it by getting money. That is why I say I desire money. Money is now the object of my desire, although it is mere means for the purpose of a desire, which is mental equilibrium. The initial disequilibrium causally makes me act according to my belief about what helps in this very case. In this way a push theory avoids the problem of intentional objects of desire and their desirability conditions, which are impossible to handle in terms of the extensionalist language of science. Any disequilibrium is causally and non-cognitively motivating and thus one can learn what to do in order to fix the problem even without thinking of it. I just do what I have learned I must do to make myself comfortable again - or, I may be conditioned to act in a functional manner. Russell says, I believe, that scratching (purpose) alleviates discomfort (desire) and hence I scratch (motions). Next, I automatically revise my belief system to the effect that scratching helps if I act accordingly. Hence, I desire scratching, which is the purpose of the relevant desire in service of the

10 B. Russell, The Analysis of Mind. London: Allen \& Unwin, 1921. I have used the Digireads. com Book, 2008.

11 Russell, 1921, p. 31. 
act cycle. This is of course unintuitive because now one desires the means and not the end-state. In other words, according to Russell, one does not desire relief but what brings about relief. Perhaps we should call it an instrumentalist theory of desire. Push and pull theories are radically different, of course. The object of desire in the pull theory is not the same as the purpose in the push theory where the focus is on instrumental desire or need: you need to scratch if you itch. However, in the pull theory what is desired is an intentional object; we think of how to get rid of the problem, when we are advised by our relevant beliefs. In push theory, desire spontaneously tracks its own disappearance, which here means something like satisfaction.

Unconscious belief: Let us next take a look at Russell's important distinction between conscious and unconscious desire because this allows us to see how different the push and pull theories really are. He says, a "desire is called 'conscious' when it is accompanied by a true belief as to the state of affairs that will bring quiescence, otherwise it is called 'unconscious.'"12 Suppose I suffer from a terrible headache and I wrongly believe that it will be alleviated by a medicine man's inspired dance around my sickbed, when explanation is brain cancer in need of surgery. Now, what I desire is the medicine man's visit and his inspired dance around my bed because I believe this helps better than anything else. Russell calls such a desire unconscious, which may sound mystical. Here is how I understand the idea. My cycle of desire and action in this case has its purpose, that is the inspired dance, and thus I aim at the best help against my present state of disequilibrium, or desire. I act accordingly. The point is that my desire for the medicine man's action brings about results that in fact indicate a purpose that is different from the original restitution of the equilibrium state of mind. I do not know what that purpose is as I think falsely that it is the equilibrium of no headache. What is the effect the dance brings about? Let us say it is the medicine man getting some money from me. This key fact is hidden from me and hence my desire is unconscious in the sense that I do not know what the inspired dance is for, hence my actions have their unintended consequences. Russell says the unconscious desire is to provide money to the medicine man. If my relevant beliefs concerning the effects of my actions are correct, they aim at the purpose that is the same as the intended purpose of my desire. This is now a conscious desire because its whole structure is transparent to me. Wrong beliefs mask the purpose so that it will remain obscure to me and in this sense unconscious.

As one may suggest, contra Russell, I do not desire the medicine man's dance because it does not help, and yet it prevents me from understanding what my

12 Russell, 1921, p. 35. 
real desire is, that is, the thing that helps. Accordingly, my real desire remains unconscious. It exists although it is unknown and in this sense unconscious. However, according to Russell, real desire is necessarily conscious. Let us see what happens here. When the medicine man dances he brings about effects I cannot see or understand. This is because I falsely expect my headache vanish. His dance serves another purpose than the original one but because I cannot understand, realise, know, or imagine what it is, it is unconscious or hidden. We can also say I confuse two different desires, that whose purpose is getting rid of the headache and another one whose purpose is unconscious to me. In this sense, some desires are unconscious because we have a wrong idea of their purpose and the effects of the desired actions. When I believe that brain surgery helps, as it does, the whole cycle becomes conscious: I will reach the purpose that is present in my mind. The medicine man's dance, on the other hand, brings about a purpose I do not know, that is, an unconscious purpose.

When the medicine man dances, what is the hidden purpose of his actions? Suppose it is wish-fulfilment. Surprisingly, Russell's theory can accommodate the Freudian idea of wish-fulfilment; or perhaps this should be expected because Russell is influenced by Freud at this stage. Now, when the medicine man dances that dance may well make me feel better. This is because I hope it works, or as I realize, hope in this case is not based on warranted relevant beliefs, which makes it a wish. I wish I become better, and hence the dance makes me feel better as if directly and not via a link to my headache. Therefore, the dance works as wish-fulfilment. I wish it helps and indeed it helps because it directly satisfies my wish. Perhaps this is how the patient reasons: I want him to dance because that alleviates my pain; he is dancing; hence, my desire is satisfied; and because my desire is satisfied, my pain is alleviated. In other words, I use modus ponens: If he dances, pain disappears; he dances; therefore, pain disappears. As I see it, most Russellian unconscious desires may work in this way. This also explains their popularity and sustainability in the long run. They work although only in the sense of wish-fulfilment. As such the dance has no relevant effect; it does not change the world in any such direction. Yet it satisfies my need for cure.

As Russell himself writes, "a belief that something is desired has often a tendency to cause the very desire that is believed in."13 Perhaps this should read: "the very cure that is believed in." He may mean that the belief in a cure is the cure. As he actually writes, he says that a belief that I have a painful situation may bring about the pain - this is true, too. By desire Russell, as we know, means the original state of disequilibrium, which does not make sense here.

13 Russell, 1921, p. 34. 
He cannot mean that, say, a belief in a brain operation may bring about painful headache. However, consider this example: I think of beer and that very thought that beer is desired makes me painfully thirsty, when drinking beer cures the desire called thirst as a lust for alcohol. In other words, a belief that something works by helping to solve a painful problem (desire) has the paradoxical tendency either to cause the very effect (cure, purpose) that is desired, or to bring about the problem (disequilibrium, desire). Says Russell, "It is this fact that makes the effect of 'consciousness' on desire so complicated." ${ }^{14}$ This is what wish-fulfilment does.

Suppose I take arsenic to cure my headache. Now the unconscious purpose is my imminent death because that is the effect of arsenic. It does not take long to learn that the method is wrong and thus the mistaken belief vanishes because it was an unconscious desire to die, as I will learn. In the case of the medicine man's dance this does not happen. The dance has no adverse consequences and therefore we have hard time learning anything from it. Yet, it satisfies my wish in the special sense of wish-fulfilment. Concerning hope, it is easy to see that we can find no role for hope in Russell's theory. Desire is an action based mechanism that works or does not work. To talk about hope is to talk about a pull theory: we hope that we get the object that exerts the pull. In the push theory, the push starts a causal mechanism that either fulfils its purpose or it does not. Hope entails a kind of psychological uncertainty no push theory may recognize. The mechanism makes me act without intervening thoughts.

Russell says, the scientifically uninformed mind entertains mostly unconscious desires, which is true. People pray for God to heal them and so they resort to wish-fulfilment: the prayer is the cure quite independently of its causal effects; here the "is" is the "is" of identity, or prayer is in itself the cure. However, what he may mean is this: when my belief system is corrected so that I learn the falsehood of my present beliefs my desire for the medicine man's visit disappears along with my beliefs. My desire was, in this way, conditional on false beliefs while the desire for, say, a surgical operation as a cure for my headache would be dependent on a true belief. But why is a magical desire called unconscious? I do not think Russell succeeds in making this clear. What he could say is that, counterfactually, if I knew that the operation helps I would desire it. In this way, my desire for an operation is unconscious, or should we say, latent. Figuratively speaking, the desire slumbers waiting my better beliefs to wake it up. Again, Russell definitely does not say so. According to him, I may think I desire something I do not desire. This happens when the chosen

14 Russell, 1921, p. 34. 
purpose does not exist, in the sense that the purported cure in fact does not work against the disequilibrium in question. In other words, when I say I desire $\mathrm{X}$, I may be wrong. I say I want to see the medicine man dancing when in fact I do not. According to pull theory, this is impossible because desire is a subjective affair. I cannot desire without believing I desire. According to push theory my existence of desire depends on the truth of some key propositions because it purports to be a naturalistic theory. It follows that I can desire without believing I desire, or I desire X and I think I desire Y.

Secondary desires: Another rather surprising Russellian invention is what he calls a secondary desire. He writes,

A secondary desire, derived from a false judgment as to a primary desire, has its own power of influencing action, and is therefore a real desire according to our definition. But it has not the same power as a primary desire of bringing thorough satisfaction when it is realized; so long as the primary desire remains unsatisfied, restlessness continues in spite of the secondary desire's success. Hence arises a belief in the vanity of human wishes: the vain wishes are those that are secondary, but mistaken beliefs prevent us from realizing that they are secondary. ${ }^{15}$

Russell's point looks like this: unconscious desire has its purpose, which I sometimes adopt as a new and known purpose. I suffer from recurring headaches and desire massage to cure it. This involves an unconscious desire because massage does not help. However, I learn that massage relieves tension by relaxing me, and hence I accept it as the new purpose. I have thus acquired a new conscious desire. In fact, I have created a secondary desire that is still tied to the primary one, the cure of my headaches, whatever it is. As Russell says, the secondary desire is problematic. It successfully serves its own purpose, that is, relaxation which relieves tension. Hence the desire is real and conscious, yet it does not eliminate the primary problem, or headache. In some cases the secondary purpose may even make the situation worse. Every time I have a headache I order massage, which indeed is dysfunctional in the long run. To follow Russell here, he says life becomes better if such secondary desires can be dropped, which in my example is quite obvious, but only if the primary desire can then be taken care of, that is, the real cure can be found. The secondary purpose offers at least some comfort to me. Anyway, the secondary desire may make the elimination of the primary one more difficult.

15 Russell, 1921, p. 34. 
The definition of secondary desire is as follows: A secondary desire is a new desire that emerges from the realization that an unconscious purpose has certain good effects. These confirm the new purpose and thus the secondary desire becomes conscious and real, when it serves the new purpose, even if it is misdirected. In the case of a secondary desire, its purpose tracks the original purpose. In the case of the primary desire, the desired action tracks the purpose. Secondary desire: I notice that some actions feel good, thus I will desire them (the means determine the goal). Primary desire: I do not feel good, this is why I will desire whatever makes me feel good (the goal determines the method).

Another example that is more in line with Russell's own rather florid rhetoric is as follows. Any secondary desire results from a misunderstood primary desire, as follows: I want to kill Bill, which desire is based on my disturbing bitterness towards Bill caused by his earlier actions. However, I believe that revenge is both morally wrong and prudentially speaking dangerous, which worries me; on this basis I do not want to kill Bill but this again entails a false belief about what would bring quiescence to me, instead of killing Bill, that is, an act omission. The omission then determines a secondary desire: I want to do nothing as I feel this helps against mental disturbance. So, in order to void a motivational conflict between killing and not killing, I want to travel around the world - this sounds like a third-level desire that is consonant with the original omission. Very quickly I notice I do not enjoy the trip as much as I should; and the reason is my primary desire for revenge, which still indicates an unresolved mental conflict. Then I go and kill Bill and return, and the rest of the trip is perfectly lovely, which shows that the belief concerning the effect of my trip was false. Russell's own exposition here is too hurried and sketchy to allow a more faithful exposition.

Desired Beliefs: Russell's third interesting point concerns desire for beliefs. This looks like an interesting topic. Suppose I believe I do not live for ever and this causes considerable discomfort to me, hence I desire eternal life. I realize this is possible only if there is a good God and, therefore, I want to believe the good God exists. I also believe God helps me, from which it follows that I can live forever. This is another instance of wish-fulfilment, which we discussed above. Russell writes,

This desire for beliefs, as opposed to desire for the actual facts, is a particular case of secondary desire, and, like all secondary desires its satisfaction does not lead to a complete cessation of the initial discomfort. Nevertheless, desire for beliefs, as opposed to desire for facts, is exceedingly potent both individually and socially. According to the form of belief desired, it is called vanity, optimism, or religion. [...] It is very largely 
through desires for beliefs that the primitive nature of desire has become so hidden, and that the part played by consciousness has been so confusing and so exaggerated. ${ }^{16}$

According to Russell, such a desire for a desirable belief, or for the truth of such a belief, is an example of secondary desire and of course of unconscious desire. As we know, a mere belief can alleviate the discomfort that brings about the desired belief in question. Nevertheless, my belief that there is a good God who provides me with eternal life may not fully justify the idea that eternal life is available, and therefore some pain continues. Russell also says that the belief in God exemplifies an unconscious belief if it is false - let us suppose so. This is to say it cannot bring about the final quiescence even if it may produce optimism and give the person more courage to meet the pain of mortal existence. Thus emerges a new desire for God's help. The belief in God works now like the dancing medicine man. Dancing and believing have their effects that are not quite what one wants, but they produce, anyway, effects that may be beneficent. But because they are not the effects that are originally wanted, they do not produce the final quiescence. The new purpose is the relief general optimism provides. All this is psychologically plausible. When I say I believe that God gives me an eternal life, this phrase hides not only the unconscious desire for eternal life but also the conscious secondary desire for a more optimistic attitude towards the ever troubling possibility of the personal end of life. Russell's ideas concerning desire are coherent and interesting but I must say they also are unintuitively formulated. He aims to refute the cognitivist non-naturalistic theories of desire and, therefore, his approach is radically different from them. However, Russell may well be right when he thinks that a push theory must be formulated in a language that does not respect the intuitions derived from a pull theory. I will argue that pull theory is more fundamental than push theory but at the same time some idea of push is needed in the complete theory of desire.

\section{Desirability Demystified}

I will defend the following position: instrumental desire or need can be understood according to the naturalistic push theory although the final desired state of affairs, Russell's purpose, can be understood only via the cognitive and teleological pull model. A simple example illustrates this. Suppose I love Mary and I want her to be mine - what it means "to be mine" is an open question of 
course but let it be so. According to Russell, this state of affairs troubles me like an open sore, and hence I desire consciously or unconsciously a cure, whose direct purpose is to make her mine and indirect purpose to alleviate my pain. I may generate a secondary desire that I should avoid and also a desire for good beliefs. The situation quickly grows conceptually complicated but then I tap my belief system and under its guidance start desiring certain best means for solving the problem and reaching quiescence.

Now, I want to buy Mary expensive and impressive gifts and ask my friends to talk to her about how good I am as a person and future husband and father. I want to believe this helps, as it indeed may, and thus I desire the whole package. Russell is an actionist theorists who puts his faith on the power of action; for instance, he would not stay put and wait and hope until Mary makes here decision about her lover, or perhaps such an omission is action, too. This is to say, for Russell, psychological causation is somehow related to the springs of action and creation of new beliefs. This also is what push means. Pain and discomfort push me to do something about it. This is what I call a motivational drive here. Its route is determined by the relevant beliefs concerning the direction where relief is to be found. Russell says the content of both attitudes should be the same, that is, what I believe and what I desire are based on an identical proposition. So, I believe X helps to alleviate my discomfort and the same $\mathrm{X}$ becomes the content of my relevant desire.

What we see here is, as I said above, a theory of the generation of instrumental desire or need. I want a new car and hence I need money that I also desire: I want the money to buy a new car. Strangely enough, Russell has nothing much to say about the final desire, in this case of the car. Why would I like to get a car, or why do I desire it? If the lack of car is simply disturbing and painful to think of why not get rid of the idea rather than start the complicated process of getting a car. The point is this: if the lack of the object or purpose of desire is painful I naturally try to avoid the idea. The desire simply pushes me out of its context because of its painfulness. We know this happens in real life and in philosophy: many theorists have recommended escape from the shackles of desire. ${ }^{17}$ But think of Bradley who says the purpose of desire is somehow necessary for the person; without it he is "void and negated." Some desires are like that, unavoidable, some are not. I want a car and I drop the desire because of the simple reason it is too difficult to satisfy. Bradley's idea does not apply to this case. A samurai has humiliated his master and now he must commit

17 For instance, S. Weil, Gravity and Grace. Tr. E. Crawford and M. von der Ruhr. London: Routledge, 2002. She writes, "Desire is impossible: it destroys its object [...]. Because to desire something is impossible, we have to desire what is nothing." (pp. 94-95). 
seppuku. He cannot drop the idea because then he really is "void and negated." Russell seems to follow Bradley too closely here.

I cannot get rid of an instrumental desire too easily if I already am committed to the purpose of it. This indicates that Russell's push theory may apply only to those cases in which the discomfort is of the type we cannot forget, avoid, get rid of, or ignore. Instead of trying to satisfy a desire I cannot drop I may try to circumvent it. Considering the push theory, one must specify what triggers off a desire, that is, the relevant cycle of actions. We do not act on any possible source of discomfort. I may well think that a given discomfort is what it is and nothing can be done about it. For instance, I have done something wrong and accept the pangs of conscience as a justified punishment. What can I do about it, nothing.

Why continue to talk about discomfort and its linguistic relatives? We can avoid it: I have plenty of wine at home but I want some more. I feel void and frustrated without this extra batch of wine, but then I tell myself that the idea is foolish and the desire vanishes - or at least it should. In many cases it does not, why? The reason is that the itch, or the discomfort and pain, caused by not storing more wine at home, refuses to disappear because more wine is such an attractive proposal; hence, the pull exhibits its typical effect here. The desire for the object or purpose is based on its pull, or the attraction of the desirable states of affairs, rather than the push generated by discomfort. Notice that the original discomfort is based on desirability considerations: More wine at home appears so good that the lack of wine feels painful. It is hard to be without good things that one believes are available. This is to say the push, or drive, is explained by desirability considerations, or attraction as pull.

Of course, it is implausible to argue that all push is generated by discomfort, analogously with physical discomfort like an itch. Such metaphors lead us astray. For instance, an artist need not feel first some acute discomfort before he can start working, as if pain had triggered off his desire to make art. It is enough that he believes he is an artist and artists do art. He formulates a normative belief to the effect that he as an artist should do art. Notice that in pull theories desire itself is not motivating unlike belief. Anyway, an artist should be interested in art; whatever that means, at least it means that an artist finds some artistic themes convincingly desirable. He becomes vulnerable to artistic desirability, so to speak. His life is characterized by sensitivity to art and hence he finds some art desirable but some, perhaps, repulsive. His values, as the normative elements of his psychological constitution, dictate what he feels is interesting and worthy of his attention and serious consideration. I do not say this example can necessarily be generalized. Its purpose is to show that desire is certainly not uniformly dependent on mental disequilibrium, discomfort, or 
lack of acquiescence. We certainly know contexts where an emerging desire is pleasant and as such eagerly anticipated and sought for. Sometimes I cannot wait to get a chance to get philosophical, say, about some arcane historical problems. Those problems pull me towards them, but I must then ask why. The answer is, because of the drive under whose influence I currently am. Desire has both a pull and push component.

\section{Push Theory Returns}

Desires must be explained. The objects of desire are desirable, but why? They are good, pleasant, or rewarding. What then is the source of the pull? At this point it is instructive to think of negative desire whose object is bad, painful, and punishing. When you look at it, it is clear that desirable and undesirable things behave in a radically different manner. Good/ bad is not a problem: you like what is good and dislike what is bad. Pleasure/pain is a problem, just like reward/punishment: you may be nonchalant about pleasure and reward, while admitting that they, intrinsically, are desirable. But their opposites are of much more serious nature. Pain is unlike pleasure in many ways. You may lose your interest in pleasure and some excessive pleasures turn into pain in the long run. But it never happens that pain turns into pleasure or that I lose my interest in it. ${ }^{18}$ Pain, and in some cases punishment as well, has a forceful and coercive quality that cannot be denied or neglected. Pain bypasses cognitive level of reasoning and reasons. Pain can grow until it is intolerable and then the victim goes into a pain shock. A person reacts to pain via drive away from it, when the drive is not a reasoned attitude. A push away from pain is a fact. What about a push towards good?

A desire that is based on good, pleasure, or reward looks different from negative desire, which is drive based unlike reason based positive desire. This is a mistake. Positive and negative desires must be in a symmetrical position concerning their typical objects. They are not two different types of desire. Therefore, if negative desire contains a push component positive desire has it as well. This is not to say that negative desire lacks a reasoned component, it does not. Suppose I cannot get a good thing without some pain. I may think the level of pain is such that I can accept it, or I may think I cannot. In the same

18 People sometimes seem to seek pain and deal with it as if it were pleasure; about BDSM and S/M, see my "A Philosophical and Rhetorical Theory of BDsm," The Journal of Mind and Behaviour 38 (2017), 53-74; and Ch. 10 of this book. Also, S. Newmahr, Playing on the Edge. Bloomington: Indiana University Press, 2011. 
way, I desire and anticipate something good. I feel the urgency of my desire and realize no reasoning can diminish it. I love Mary who loves anybody else than me. Is my desire here negative or positive is hard to say, but the urgency of my attitude cannot be denied. My conclusion is that positive desire has its urgency level that we can explain in terms of push or drive. In positive desire we find a component, drive, that is not cognitive or reason based or voluntary.

This is to say that I find an object desirable in the sense that I would like to see my actual world change into a better possible world such that the object occurs there. However, this is not yet a satisfactory description of the situation because in normal cases I feel for it and am ready to invest into it. Sometimes my desire is a strong urge that I am afraid I cannot resist. Some desires are weak and meek, some are demanding and strong, some are overpowering. They have what I call here a variable urge factor. This entails a cause or, as I put it, drive. I am serious about the change of worlds, I tend to focus on it, I do hate to miss the opportunity, I wait for it to happen, or I invest in it somehow - but notice this may not include action, not even in counterfactual sense. I may invest much, sometimes so much an outsider cannot figure out why. In the case of an obsession or addiction the investments may indeed be irrationally high and, moreover, I myself may realize that this is the case. ${ }^{19}$ Such situations are irrational or even pathological, but as such they do not interest us here except as reminders of the strongest urges. Also, cases where I say I desire something but pass it by, or fail to invest anything much at all in it, are anomalous in their own way. These cases may exemplify a confusion between actually desiring and recognizing desirability. We find many things desirable that we never desire or even come close to desiring. They may be somehow below me or as well above me, or to put it colloquially, they are not my cup of tea. Some desirable things get buried under other desirable things - you should not want everything as you will learn early on. You must choose. Many other psychological reasons exist for neglecting objects that as such are desirable. An interesting case is this: desirability ascriptions apply to a broad category of things, so broad that I find it too tedious and difficult to select one specific item that I desire. This is a well-known problem in consumer research: I go to a supermarket to buy tea and hence I presumably want tea. Yet I do not buy tea because I cannot choose from their excessive selection. I decide to postpone the acquisition by utilizing some more or less self-deceptive moves, for instance, I say I still have some tea at home. I want tea but I find out I do not want any of the displayed packages. In other words, the drive is still there although corresponding the attraction

19 See N. Heather and G. Segal, Eds., Addiction and Choice. Oxford: Oxford University Press, 2017. 
has vanished. I am unable to feel for any of the offered items and therefore I fail to invest in any of them. The self-deception shows that the drive remains.

Now, desirability is a necessary condition of desiring but what is the sufficient one? How and why do I move from a desirability ascription to actually desiring something, which entails a commitment to the case and willingness to invest in it? As I said above, I want to argue that it is a matter of a combination of my relevant drive (push) and the attraction (pull) of the desirable object, or an interplay between them. If I am not pushed, I may well consider a state of affairs desirable, even very desirable and as such tempting, without committing myself to it. I am not ready to invest in it. We find two distinct but not mutually exclusive possibilities here: the causally efficient push (drive) and its level of urgency can be explained by my beliefs concerning the situation, or it is based on some causally relevant, psychological background conditions. The two alternatives can be called cognitive and naturalistic.

A paradigmatic example of the naturalistic case is hunger. Food deprivation causes a bodily state called hunger, I have learned how to free myself from it, I believe that eating helps, and I eat. At some stage of this chain I may say I want food and start the relevant behavioural cycle that hopefully ends up in a better possible world where I am no longer hungry. All this can be explained in terms of Russell's theory of desire but it is easy to see that we need more. The naturalistic theory fails to explain the selection of the object of desire. I may be hungry but I do not want eat because no food looks desirable to me, and hence my prospective desire fails to emerge. I say, I need to eat and I would like to eat if I found edible fares. Drive is then necessary but not sufficient, as I said above. Of course most cases of desire are not as simple as hunger but a causally created drive is still necessary for the agent's prima facie commitment to the case. Think of emotions like anger. They often bring about relevant desires, like the desire to get even, which sometimes is so urgent that the selection of means can be less than perfect. Most emotions create drives, and this is true of positive emotions as well, which then lead to desires whose satisfaction modifies the emotions in the right way. ${ }^{20}$ Many emotions bring about relevant desires, hence the drive is there, too. Emotions also make us committed to certain strategies of desire. Once the person is committed, she needs an object that cannot be chosen in terms of causalistic considerations alone. I feel strongly

20 I cannot go here into the details of the effects of emotions on desire. See for an empirical study in behavioural economics, D. Ariely, Predictably Irrational. New York: Harper, 2008, Ch. 5. Emotions change the agent's reasoning and valuation and this influences of what she takes to be desirable. The push theories can easily accommodate such results. An object, A, is not seen as desirable but A accompanied with a suitable emotion is desirable. 
amorous and thus I want a sex partner tonight but I do not find any of the possibly willing partners desirable. Here the urgency of my desire (drive) makes me naturally less selective but still leaves some room for deliberation. This may not always be the case when the urge is extreme. The pull factor does not vanish easily, or the desirability conditions remain.

Let me then get back to the hunger case. My bodily deprivation generates a drive that pushes me away from the hungry state towards a new equilibrium, which I consider essential to my well-being. Next, I believe I need food and I say I want food, I choose what food I find desirable - if I have a choice or the drive is not overwhelming. I eat and that leads via a causal chain back to bodily equilibrium. Now I feel no hunger. Notice that in this case we normally speak of instrumental desires or needs as if they were the final desire and its goal. The reason is that eating food causally and as if automatically takes care of the hunger problem. Nevertheless, in this case eating is not the final desire but mere means.

Suppose I want fine food, which means hunger may be absent. I eat because fine food is attractive for me as such. I expect some enjoyable aesthetic and culinary experiences, I believe people in my position are supposed to eat fine food, and I am fully aware of my future bragging rights. In this case the drive is constituted through a complex system of personal and social beliefs, or expectations of the basis of such beliefs. As Russell says, all these beliefs are desirable beliefs in the sense that I am at least comfortable with them, or they are actually desirable and as such attractive to me. It follows that I want these beliefs, which is to say that my belief induced drive cannot be based on them. On the contrary, we must locate the factors that generate the drive in question at the deeper psychological level. In the case of fine food I have learned that these beliefs, which are now desirable as such, have been good and beneficial to me earlier. In other words, I believe that these beliefs are desirable as such and, moreover, I do not see any reason to negate them just now. Obviously the problem of belief based motivation has moved to a deeper level and so we need to ask whether the deeper beliefs as ur-beliefs are causally generated, as they should according to this naturalistic model of motivation.

Suppose I want to be a good father; what are my drive related ur-beliefs that explain my desire for the beliefs that I happen to desire in this case. We can use a reduction argument here as we must locate some beliefs that are not desirable as such but can explain the desirable beliefs that motivate the desire and explain its generation. Without such beliefs my desire is floating in thin air. It has no foundation. The only possible foundation seems to be a causal one, namely, in the course of my life all kinds of events and perceptions have causally generated beliefs in me such that they explain my desirable beliefs 
that contribute to the creation of my ideas about what I want and why, that is, my desire oriented drive. For Russell, these experiences are always painful experiences of lost equilibria but this is obviously too narrow a view. The earlier experiences that generate our motivating ur-beliefs allow for a wide variety of situations, both pleasant and painful. Moreover, they need not be closely connected to desires that they generate according to the push model. The belief chains may be long and varied; who can say what experiences ground my desirable beliefs concerning the possible world where I am a good father? Good people have such-and-such beliefs about good fatherhood and hence those beliefs are desirable. I do not think a philosopher should try to go any deeper on this empirical psychological issue.

Notice that such psychoanalysts as Jacques Lacan and writers like René Girard claim that our desires are social copies or they are acquired through mimetic processes. ${ }^{21} \mathrm{I}$ cannot take a stand for or against such a theory here, yet it illustrates my view as stated above. Human beings are social creatures whose biology is tuned to social life and made sensitive to social cues. Clearly a causal connection exists between other peoples' desires and mine, simply because my social existence is impossible without my ability to copy desires and hence the influence of others to me is necessary and automatic. It is independent of my efforts and beliefs. I may sincerely believe their desires are crazy and yet I mimic them. Such desires may hurt me but that does not matter. I live my life copying some desires and rejecting others but I must copy a large number of them and do it again and again. All this starts when I am very young so that at this developmental stage the generation of my desires must be automatic and as such causally grounded. When I am a mature and rational adult I am able to manipulate to certain degree the desires that enter my social life through mimesis. I may reject some and adopt some, not really freely but still not deterministically either. My ur-beliefs must, nevertheless, be causally formed so that with their help I can figure out what later beliefs are desirable and what are not. All this contributes to my motivation that provides the drive towards certain objects and allows me to commit myself to certain selected desirable states of affairs and the related instrumental beliefs. In a word, a hidden push can be found however deeply it is buried and hidden in my epistemic system. Without it no pull can do its work, but without the pull no desire may make sense to me personally. I need to commit myself to some, and only some, attractive possibilities and go along with them.

21 R. Girard, Deceit, Desire, and the Novel. Tr. Y. Freccero. Baltimore: John Hopkins University Press, 1965, Ch. 1. 
The last but not the least question I ask is, what explains the strength of desire, that is, the urgency or the degree of my personal investment in its object? The answer is, not the degree of attractiveness or desirability of its object but the strength of the push. Notice that very strong desires, or urges, are sometimes independent of the quality of the object once it is desirable per se. Those who really want strong alcohol, drink anything, whether it is desirable as such or not. They no longer care of what they consume. Perhaps, if push is weak the emphasis on desirability is strong and the other way round, strong push entails a diminished importance of the pull. A strong urge is not going to be stopped or sidestepped only because some attractive objects are unavailable. A starving person eats anything. A gourmand does not want to go hungry because he wants to enjoy his meals. However, in some cases such an inverted scale may not apply. A true wine connoisseur is supposed to enjoy a strong pull and strong push at the same time. Perhaps this is an illusion. Anyway, the main point is that I may not desire a fully attractive object and I may desire a less attractive one. My conclusion is that pull or desirability explains the direction and meaningfulness of the desire towards certain objects and push or drive explains its urgency, which again explains the amount of my investment in the object. 